\title{
Bringing Technology in the English Classrooms
}

\author{
Kamali Kanta Bhetuwal ${ }^{1}$
}

\begin{abstract}
Technology is one of the crucial and inevitable parts needed in twenty first century of the educational world. It is very important and challenging aspect in language education which is discussed below in this article. Human behavior is affected by technology is also highlighted in this article. How the language instructors bring effective and essential technological tools in English classrooms to enhance and promote learning of the students. Technologies provide a pedagogical basis for understanding how students learn and some of the approaches to teaching with technology use the best technological tools, and appropriate type of instruction to enhance learning under Bloom 's taxonomy are included. So, the technology offers for education and learning. Technology is now very essential in education, not only to the learners but to the instructor and school manager as well. Instructors must be on the edge of updating themselves in the integration of technology in teaching. Research must be conducted apart from what has been published. More articles are needed to publish to add more learning to the students and teachers to enhance in their learning through the incredible support of technology. Students should be provided ample opportunity through it to save their possible future that only can open the door of success in their learning.
\end{abstract}

Keywords: $C M C$, digital literacy, $C A L L$, language skills

\section{Computer Mediated Communication (CMC)}

Computer-mediated communication (CMC) is defined as any human communication that occurs through the use of two or more electronic devices. Computer-mediated communication $(\mathrm{CMC})$ is an umbrella term that encompasses various forms of human communication through networked computers, which can be synchronous or asynchronous and involve oneto-one, one-to-many, or many-to-many exchanges of text, audio, and/or video messages. $\mathrm{CMC}$ examples include email, network communication, instant messaging, text messaging,

1 Mr. Bhetuwal is a lecturer of English Education at Koteshwor Multiple Campus, Koteshwor, Kathmandu affiliated to T. T. He is a Ph. D. scholar at Graduate School of Education, T. U. 
hypertext, distance learning, Internet forums, USENET newsgroups, bulletin boards, online shopping, distribution lists and videoconferencing.

Communicative exchange between participants using a computer exchanges are recorded and information on performance such as keystrokes, erasures and times can be documented. Data: there are many forms of second language data. For example, data may be oral or recorded onto audio and /or video types; they may be written, in the form of essays, test scores, diaries, or check marks on observation schemes, they may appear in electric format, such as responses to a computer-assisted accent modification programme; or they may be visual, in the form of eye movements made while reading text at a computer or gestures made by a teacher in a classroom.

Methods for reporting are telephone calls (or e-mails) home, reporting outstanding performance as well as concerns.

\section{Need of Digital Literacy Education}

It is one of the burning issues to promote and enhance digital literacy along with basic literacy in Nepal. The present day world has reached towards digital knowledge crawled from recognition of letter. The traditional concept of literacy is to know to write and identify the letters from the text but the modern definition of literacy opines that to understand the meaning of word and to know the advantages of the meaning of text. UNESCO defines literacy as to know the context and understand its meaning through the process of creativity, utility with technological appliances and tools. Digital literacy has developed personality of people and of quality of education. The slogan of international literacy in accordance with UNESCO is "literacy in digital world". It is a bit clearer that universalisation, globalisation and rapid development of informational technology have changed and reformed literacy in the global scenario(UNESCO, 2019).

"To be truly empowering, new technologies must stand on two pillars," said UNESCO Director-General Irina Bokovaas after opened the International Conference on International Literacy Day at Paris Headquarters, which focuses this year on Literacy in a digital world. "First, they must be inclusive, bridging gaps, not deepening them. Second, they must be underpinned by respect for human rights and dignity. All this gives rise to new questions about the meaning of literacy today." 
"Traditionally, literacy has been considered a set of reading, writing and counting skills. The digital world calls for new, higher-level, competences on top of these,"'(Bokova,2019)

The present day world is largely associated with digital environment. Digital technology has brought rapid and drastic change and reformation/ transformation in the lifestyle, learning styles/strategies and socialisation process of people. The positive result that the digital technology/ literacy has brought the following things in human civilization such as management of knowledge, networking ,social service ,industrial production and has opened the door of novelty. Literacy is one of the basic pillars of human development. Digital literacy and information technology are one of the by-products of learning English as an international language/lingua Franca.

Online education, distance and open education, modern teaching methods have given ample opportunity to the people of $21^{\text {st }}$ century. There is commercialization and privatization in formal education and this made education expensive but due to the spread of technological development lifelong education and behavioral education have been possible even staying at home freely. The means of communication online, social networking, different website are true enemy but best friend for the knowledge and information.

There is not only the less literacy education in Nepal but also the people have well access in technological education. The use and density of mobile phone is distributed and utilized high but there is a poor excess to the internet. Due to the lack of digital literacy there is a negative impact and misuse of the online social networking. In the context of Nepal, information technology has created downward mobility of the people due to the misuse of the technology and its expenses. It has also brought negative perception in the family and society.

Cybercrime is increasing due to the misuse of technology and the people have started to forget to read and write correct spelling and grammar of both mother tongue (first language) and second language too. Universalisation of the global world technology has made the whole world a global village. If the technology education through English is promoted and enhanced, the positive message will be seen in the world. In the context of Nepal, different literacy has been updated and changed (transformed) into e-Library; language labs have been established to enhance the digital need of the language learners from the very beginners. 


\section{The Contribution of Technology in English Language Classroom}

TELL has brought the superb contribution in learning English and facilitated in classrooms. Technology is thoughtfully, carefully integrated into the course. Educational technology in teaching and learning is very important and challenging aspect in higher education. According to Wilson and Freeman (2011), Teaching and students benefit from technology's presence and its impact that changes our vision in education and ensuring efficiency and effective integration. Technology has now changed how teachers and students access, gather, analyse, present and transmit information by giving them more power in the classroom (Dooley, 1999). It has helped to sign up for email, updates, text messages alert to receive assignments and reminders for activities in the classroom. Technology has been increasing performance and changes our vision. It has become a part of course in universities and has been helping and promoting for effective learning.

Computer software tracks students' progress. Vigotsky, Bruner focused on the demonstration of knowledge through creativity and collaboration. Dewey:, real world, practical workshop, directed living, Chomsky's idea on, there is no rote and memorization, language is innate, formal /universal grammar and has focused on good habit and thinking to creativity.

Likewise, Bloom'sidea is, knowledge (cognitive), attitude (affective), psychomotor(skill) have been claimed to the higher level of thought. Learners become much better, if students are helped by technology, get opportunity to be with native speakers tutored by native speakers to practice pronunciation, listening, recording of their voice, language lab, audio-video tapes, DVD/internet ,TV movies( to learn L2). Portable handheld devices such audio, video players, digital books, smart phones, personal response system are some of technologies used in classroom.

Web connectors such as online course, course management system, social networks, and blogs are also used. Some of the networking sites for learning language are, YouTube, my space, twitter, Skype, face book, Gmail, yahoo, imo, viber, website, blog, Google, podcast.

Some of the teaching sites are; Camtasia studio, animo to, picture trail, video tutorials, power bullet, a flash movie creator, sharing presentation documents, pdfs, videos, webinars, slide shares, spelling grammar check, web search engine, like google, online dictionaries, online translators. Technology not only degrades the learning performance of the students 
(negative effect) but also improves and enhances learning performance of students (positive effect). CALL is a historical model for language learning and we consider here the various roles that technology can play in learning in relation to theories of learning.

Warschauer considered that there were parallels between a changing view of language and the development of educational technology. Warschauer believed the three phases of CALL Structural CALL. It is the first phase which is based on the language as a formal system of structure that is grammar, phonology etc.), focuses on drill and practice methods to achieve accuracy, grammar translation method and audio-lingual approach to teaching language and were popular at a particular time. Here, this type of structural CALL (Bax, 2003) called restricted CALL. (Closed, restricted, this approach is largely a historical artifact that is now rarely used.

Communicative CALL : Next model or second phase : Knowledge about language is constructed or made in the learners' mind rather than the formal system or rules, here communicative language teaching (CLT) is a dominant methodology. Bax proposed or named it as an open CALL for this model. (Persisted from 1990 till today) and advocates open-ended interactions with both computers and rarely with other rules.

Integrative CALL .Bax says this third phase of model as integrated CALL. Warschauer talks about multimedia and the internet which in earlier $21^{\text {st }}$ century was still tied to desk based computers .But Baxfavours or foresees devices that are very different in shape and size. Bax argues again that CALL is no longer a meaningful construct because technology (digital device) is an inseparable part of everyday life and teaching; he further says that there are many teachers who feel that educational technology is still an area that they need to learn. The concept of normalisation with regard to Bax's third phase of CALL that is integrated CALL, he argues that when new technology is introduced, people react strongly whether with alarm or with awe (mix of fear and wonder), make the people transform their life. Bax and Woolgar say that social and cultural factors influence even determine the process of normalisation

Tutor: computer plays one of the tutorial roles in learning (language). Computer teaches the learner. A drill and practice applications, here it means skinner's behaviourist paradigm (underlying learning theory), there is more to learning a language than simply knowing vocabulary and the rules of grammar. Drill and practice programme still have a place. Independent revision, and learners often feel secure by drill and 
practice activities, mobile use for example Smartphone apps, here learners can use them independently. In short span of time even while waiting for a bus. Through the use of mobile different interactive exercise, multiple choices, short answer question, gap filling are done rapidly. Authoring softwares allow teacher to create a bank of activities that provide rapid formative feedback to the tutor.

This movement is based on the constructivist paradigm (stemmed from Piaget), here the learners have to construct knowledge through experiences, accommodation and assimilation

Papert,(2012)argues, children learning to programme computers, they can make video or audio materials and can publish their work through the internet, where they get wider audience and spectators who are less in numbers in their classroom, learners can use other web-based media such as blogs, presentation, animation, slideshows etc. that can be published in online (it is the strongest argument for using technology).Taylor's third role is computer as "tool", means the technology is the means by which a task is achieved. There is no assumption either that computer will teach or that computer needs to be taught.

Computer as a tool: word processing programme to write an essay/ editing software to create video, so it is the act of writing or editing that facilitates learning rather than the use of technology. Internet and smart phone have arrived and the role has been extended into one that mediates communication and interaction between people, finally this leads towards social constructivism (Vygotsky, 1978) learning is constructed first through social interaction and then on the individual plane, Vigotskysays that is ZPD (zone of proximal development), the learner can achieve when working in collaboration, learning takes place between more peer(scaffold for other party) where the knowledge is built and the collaboration benefits both the partners. Bruner, (1999)says scaffolding supports the child linguistic development, language is a tool like computer that develops primarily through social interaction. He says more able supports to less able and learning takes place smoothly. Social constructivism can also be seen as the foundation of communicative approaches to language learning which learners engage in activities which force them to talk to each other, so this theory is related to language learning theory such as Krashen's,(1997), concept of i+1(environment where the learning takes place through the exposure of inputs. Computer as a tool is a type of environment that is other way of technological resources. Digital technology has created new contexts in which people can engage in shared activity and build community, here we 
say COP (communities of practice). Gee, (2005) points out that there is nobody of expert members at the heart of the learner community in the classroom, however digital networks like internet communities, social networks, online games) offer genuine COPS. COP is also likely to be a discourse community (Swales, 1990). Siemens argues that learning occurs through engagement with a diversity of ideas and opinions and that knowledge may reside in machines. He says people use machine to store their knowledge. The internet provides a vast repository (where things are stored) of knowledge. Computer as a tool is, the first resort of $21^{\text {st }}$ century information seekers. Even academics nowadays are likely to begin work on a literature review by searching database (electronics).

Tool: (considered as the resource). Steven,(2011)says the examples of technology PowerPoint, interactive whiteboard for teaching cormier's,(2008),connectivist theory derived from the rhizomatic knowledge, he says knowledge is not platonic( existing in its own right), but is rather located in the mind of many individuals and ideas constructed through shared thinking and conversation. A living language is not fixed, but is constant state of change like rhizomatic plant moves through the soil, so the technology assists with this process like the relation between plant, soil and environment . Technology leads to development like blog, internet, and laptop but also facilitates the rapid spread of new knowledge and mediates human interaction. Crystal,(2007) says instant message, mobile text message, punctuation, abbreviation, for example, 18 meaning "late" in English (rhezomatically it happens through the spread of technology as a tool .To manage the technology we need to be able to use language appropriately. Simpson, (2005) talks about electronic communicative competence. Walker, (2007) says technology is not only about communication. Canale and Swain (1980), the model of communicative competence is given below: Linguistic competence: one of the model/ element of communicative competence as proposed by Canale and Swain (1980).It means how the language works, how sounds are fit to make words and words to sentences (grammatical).Sociolinguistic competence: means how the language is used in setting / context, or how words, phrases and sentences are used in appropriate situation to achieve desired communicative purpose. Discourse competence: is ability to create and use larger pieces of language to create texts or conduct conversations. Strategic competence: is the ability to manage and navigate communication to repair communication breakdowns and work around unfamiliar area of language. Procedural competence: one of the elements of 
DC ability to manipulate in terms of hardware and application, or knowing how to use the technology like how to switch it on, which buttons to click etc. Language means knowing the grammar and vocabulary, so the basic skills of DC and IT training courses focus on this aspect of competence, to use in different social-context in terms of both technology and language. Deciding whether it is appropriate to use social media, such as, Facebook etc.

It is the overlapping between technological competence and communicative competence.

- Technology always impacts language (how):Ability to manage an extended task using several applications and or types of equipment. Ability to record, edit, and publish a video or to write a blog post with photographs. Ability to repair problems .Ability to think of alternative routes and options. Be able to repair both communicative and digital problems.

- Being able to switch the channels: Contacting someone by email, or social networking, if not answering in time rescuing the deleted documents.

So, in nutshell, DC is important because it provides a mechanism for diagnosing, understanding and repairing digital needs of the learners. CALL andTELL, the main difference between two is just technology, not supporting language learning are both part of environment in which language exist, so it is used. Both provide new context and are the new tools for communication. TELL is the wider range of device than CALL, normalized in daily life. Both are potential for something new and are surprising and exciting.

\section{Conclusion}

Technology is necessary in today's world and we must be ready for it. Parents want their children to graduate with skills that prepare them to either get a job in today's marketplace or advance to higher levels of education and training. Employers hire employees who are reliable, literate, and able to reason, communicate, make decisions, and learn. The Department of different faculties/streams and other federal agencies recognize the essential role of technology in 21st century education. Rushin(2003). most of the English language teachers have experienced the use of technology in the classroom. It helps make a better teacher. When students see their teacher trying new 
things, they become more engaged in the process. Technology allows students to see the whole world as a resource with themselves being in charge of their destiny. It also benefits students because they have choices and opportunities to explore and share information to a greater extent than available in a traditional classroom.

Technology is a versatile and valuable tool for teaching and learning. The most important thing is that teachers need to be prepared to use these technologies effectively. Schools and colleges can use technology effectively and for the welfare of students, teachers and society. Computers can provide universal success by dividing lessons into segments to the extent needed to make sure that everyone can accomplish something. They deliver results accurately and quickly (Bennett, 2002). The closer the connection between the action and reward, the more valuable and more effective is the reward. With computers and technology, learning can be a 24/7 process. Teaching will not be bound by time constraints.

\section{References}

B. Moon (Eds) Learners and Pedagogy. London: Paul Chapman.

Bennett, R. E. (2002). Inexorable and Inevitable: The Continuing Story of Technology and Assessment. The Journal of Technology, Learning and Assessment, 1(1). Retrieved from https://ejournals.bc.edu/index.php/jtla/article/view/1667

Bruner, J. (1999) Folk Pedagogies, in Foundations of New Reform, in J. Leach \&

Canale, M. and Swain, M. (1980). Theoretical bases of communicative approaches to second language teachingand testing. Applied Linguistics 1 (1), 1-47,London: London Group Ltd.

Chen, Irene and Jane Thielemann (2008).Technology Application Competencies

Crystal, D. (2007)Language and the Internet:Cambridge University Press, 2007, P.318

Dunn, Dana (2011). Best Practices for Technology-enhanced Teaching and educational technology july-August (papert 2012)

Fasold, Ralph W. and Jeff Cannor-Linton (2006).An Introduction to Language and 
For K-12 Teachers.Information Science Pub: Hershey, New York.

Hefzallah, Ibrahim (2000). The New Educational Technologies and Learning.

Jackson, Steven; Pompe, Alex; Krieshok, Gabriel (8-11 September 2011). “The Work to Make a Home Network Work". Washington. pp. 283-90.

January 2014Early Childhood Education Journal 42(1) Learning:Connecting to Psychology and the Social Sciences. Oxford Linguistics. Cambridge University Press: New York.

Rushin (2003).Reading Comprehension on the Internet. The Reading Teacher, 56(5), $458-564$.

UNESCO (2008), 15 p. ICT competency standards for teachers: policy framework University Press, New York.

Vygotsky, L. (1980) Meets Technology: A Reinvention of Collaboration in the Early Childhood 